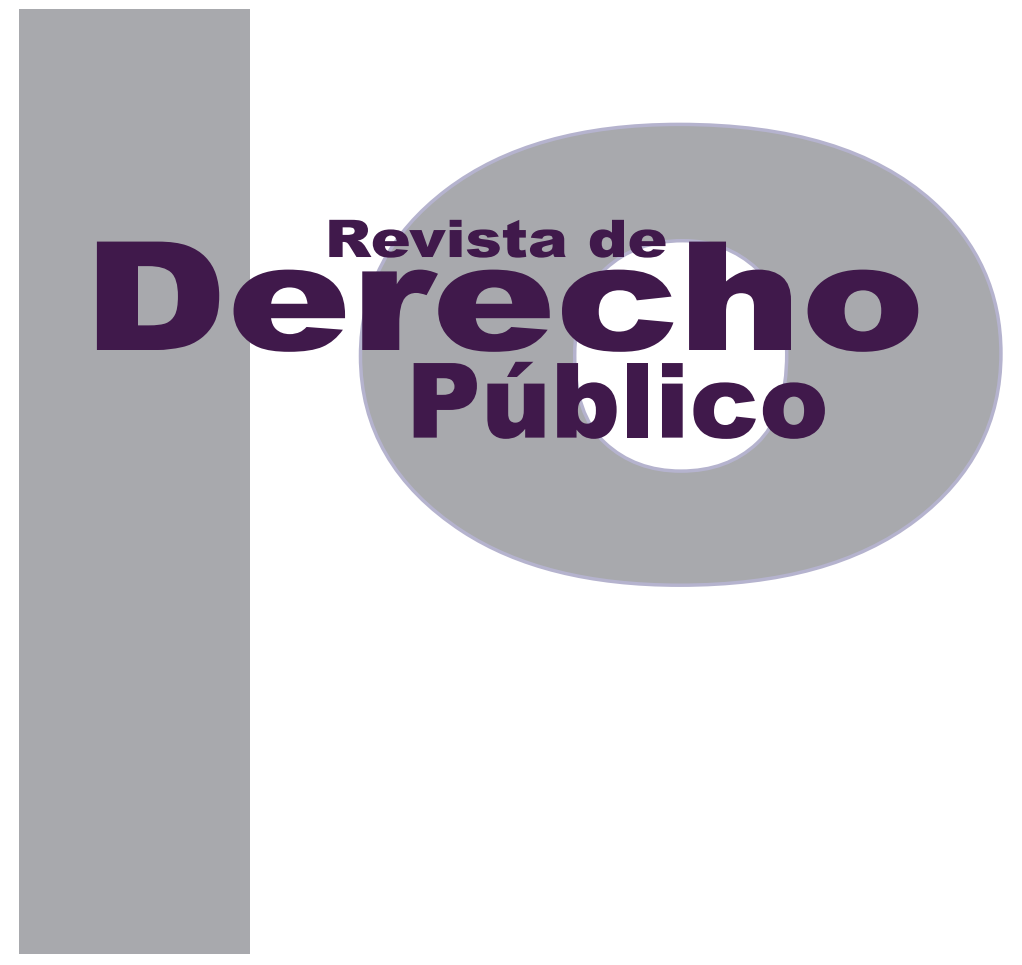

\title{
LOS DERECHOS SOCIALES COMO HERRAMIENTA PARA LA CONSOLIDACIÓN DE LA DEMOCRACIA
}

\author{
Hernán Darío Martínez Hincapié \\ GREGORY MORELO LÓPEZ \\ Documento de reflexión no derivado de investigación
}

DOI: http://dx.doi.org/10.15425/redepub.34.2015.02

Universidad de los Andes

Facultad de Derecho

Revista de Derecho Público N. ${ }^{\circ} 34$

Enero - Junio de 2015. ISSN 1909-7778 


\section{Los derechos sociales como herramienta para la consolidación de la democracia}

\section{Resumen}

El presente escrito de reflexión pretende evidenciar, desde el contenido de los derechos económicos, sociales y culturales, la relación existente entre estos y la consolidación y resignificación de la democracia a partir de la participación ciudadana en la estructuración de políticas públicas y la protección judicial de los derechos enunciados.

Palabras clave: derechos económicos, sociales y culturales; Estado social de derecho; democracia; participación ciudadana; políticas públicas.

\section{Social Rights as a tool for the consolidation of democracy}

\section{Abstract}

This paper aims to demonstrate, from the essence of the Economic, Social and Cultural Rights, the relationship among such rights and the strengthening and redefinition of the democracy base don't he citizen participation by means of public policy structuring as well as the judicial protection of the Economic, Social and Cultural Rights.

Keywords: Economic, Social and Cultural Rigths, Law and social state, Democracy, Citizen Participation, Public policies

\section{Os direitos sociais como ferramenta para a consolidação da democracia}

\section{Resumo}

O presente escrito de reflexão pretende evidenciar, desde o conteúdo dos direitos econômicos, sociais e culturais, a relação existente entre estes e a consolidação e ressignificação da democracia a partir da participação cidadã na estruturação de políticas públicas e a proteção judicial dos direitos enunciados.

Palavras-chave: direitos econômicos, sociais e culturais; Estado social de direito; democracia; participação cidadã; políticas públicas. 


\title{
Los derechos sociales como herramienta para la consolidación de la democracia*
}

\author{
Hernán Darío Martínez Hincapié** \\ Gregory Morelo López ${ }^{* * *}$
}

\section{SUMARIO}

Introducción - I. DEL ESTADO LIBERAL AL ESTADO SOCIAL Y CONSTITUCIONAL - II. BREVE APORTE SOBRE LA FILOSOFÍA Y CONTENIDO DE LOS DERECHOS SOCIALES - EL CONTROL SOCIAL, LA DEMOCRACIA Y LOS DERECHOS ECONÓMICOS, SOCIALES Y CULTURALES - IV. LAS POLÍTICAS PÚBLICAS Y LOS DESC - V. CONCLUSIONES - Referencias.

* Cómo citar este artículo: Martínez Hincapié, H. D. y Morelo López, G. (Junio, 2015). Los derechos sociales como herramienta para la consolidación de la democracia. Revista de Derecho Público, 34. Universidad de los Andes (Colombia).

Artículo en el marco del proyecto de investigación en curso denominado: "Criterios de justiciabilidad de los Derechos Económicos, Sociales y Culturales en Colombia y su aplicación en los Tribunales de Medellín», financiado por la Universidad de San Buenaventura, Medellín.

** Abogado, magíster en Derechos Humanos y Derecho Internacional Humanitario de la Universidad Sergio Arboleda, docente investigador Universidad San Buenaventura - Medellín. Correo: hernan.martinez@usbmed.edu.co.

*** Estudiante de quinto semestre, Facultad de Derecho Universidad Santo Tomás - Medellín. 
Introducción

La incursión del denominado Estado social de derecho en los modelos estatales presupone una norma constitucional de naturaleza humanista y reivindicadora de la dignidad y el ser humano.

En este escrito se pretende, a través de la descripción y análisis de conceptos y criterios hermenéuticos, dar alcance de forma teórica y doctrinal a la relación fundamental entre el ejercicio de protección de los derechos económicos, sociales y culturales (en adelante DESC) y la consolidación de la democracia como mecanismo legitimador de la eficacia directa del Estado social de derecho, tal y como lo propone la Constitución (CConst., sentencia T-406 de 1992).

La protección y garantía de los DESc se refleja en las denominadas políticas públicas, y se traduce en acciones estatales de acceso y satisfacción de las necesidades básicas en ellos contenidas.

Dichas políticas públicas son el resultado cada vez más recurrente del ejercicio del control y participación social que une de forma directa la exigibilidad de estos derechos con la consolidación de la democracia.

El planteamiento que se expone en este escrito intenta establecer una relación directa entre la exigibilidad de los DESc, a partir de la participación social en el control anterior (construcción) y posterior de las políticas públicas, como eje que fortalece los valores democráticos.
La reflexión aquí expuesta desarrollará en tres subtemas la relación entre el Estado social y constitucional de derecho y el ejercicio del control político como eje dinamizador del ejercicio pleno de los derechos sociales, que describirán teóricamente los escenarios de control social, consolidación de la democracia y los DESC.

\section{DEL ESTADO LIBERAL AL ESTADO SOCIAL Y CONSTITUCIONAL}

La creación del Estado moderno, denominado Estado liberal, implementó una dinámica legal y constitucional que no utilizaba ni incluía de forma importante los derechos sociales y con ello se generalizó una suerte de sociedad insolidaria. De esta forma, imperaba la propuesta de la prevalencia del mercado y, solo en este escenario, los sujetos satisfacían sus demandas de bienes básicos y necesidades sociales, es decir, se subordinaban los elementos políticos, jurídicos y axiológicos a la racionalidad del individuo con respecto a la ley y la propiedad como derecho esencial que lo convertía en ciudadano y con ello su protección esencial. Este modelo se estructuraba alrededor de una concepción soberana de cada individuo que tenía poderes sobre lo colectivo y lo general, capaz de ejercer sus propias capacidades sin más limitaciones que otros derechos ajenos, una especie de "espacio vital" y por ende los derechos sociales constituían una amenaza a la mencionada esfera privada (Baldassarre, Villar y Perea, 2001, pág. 15). Lo anterior le permitió al capitalismo dominar en los siguientes treinta años, una época dorada de trabajo-ganancia-mercado, 
pero aun así no desaparecen las desigualdades sociales. Se socializa el derecho con consecuencias ambiguas.

El modelo nace como una propuesta política, y posteriormente trasciende a la esfera jurídica con la consagración constitucional y la eficacia directa de esta norma constituyendo un límite a la discrecionalidad del legislador (Baldassarre et al., 2001), proceso que se amplió a los derechos sociales y que tuvo su consolidación plena en la labor jurisdiccional, por cuanto el cambio de paradigma del modelo constitucional permitió tanto reconocer nuevas garantías (no solo libertades negativas) como asignarle un papel protagónico a los jueces, en la función esencial de proteger los derechos humanos no respondiendo a criterios topográficos o de ubicación normativa, sino a su contenido, finalidad y contexto.

Como respuesta al anterior modelo surge la opción de crear un Estado más interventor, preocupado por las necesidades individuales y sociales, dotado de legitimidad siempre que se acerque al ciudadano y le permita participar de las decisiones que lo afecten, que distribuya los recursos y bienes primarios escasos dependiendo de la situación o condiciones de vulnerabilidad de las personas que no puedan por sí mismas superar su situación de indefensión. Estas propuestas estatales alternativas proponían un esquema de integración y la eliminación de la discriminación estructural y sistemática que imperaba en las sociedades netamente liberales, que tomaron impulso mediante el ensayo revolucionario dado en el viejo imperio ruso; otros procesos sin éxito fueron los de la Constitución de Weimar de 1919 y la República Española de 1931. Al final de la segunda guerra mundial se presagia la crisis terminal del dominio capitalista, mientras se multiplican las luchas sociales y crece el poder social y político de los trabajadores. Se produce el pacto keynesiano, una especie de acuerdo entre capital y trabajo.

Es indiscutible que la vigencia y eficacia de los derechos económicos, sociales y culturales dependen de una conexión directa con el principio constitucional del Estado social de derecho, que supone el despliegue de todo el aparato administrativo, judicial y legislativo de tipo estatal para dar cumplimiento a la justicia social que, además de acercar el Estado a los ciudadanos, permite el ejercicio adecuado de las libertades bajo modelos de igualdad material constitucional (cN, art. 13), lo que implica implícita y explícitamente obligaciones institucionales y sociales como la dirección general de la economía por parte del Estado para regular el mercado y propiciar condiciones antimonopolizantes y dignificantes del ser humano (cN, arts. 365-370); igualmente supone una compleja estructura de acercamiento y asistencia social al ciudadano, así como la promoción de condiciones materiales mínimas de existencia, de las cuales dependerá el ejercicio de todas las libertades exigibles judicialmente (Gutiérrez, 2010, pág. 83). 


\section{BREVE APORTE SOBRE LA FILOSOFÍA Y CONTENIDO DE LOS DERECHOS SOCIALES}

Tradicionalmente los DESC han sido categorizados como pautas políticas o policies en términos de Dworkin, negando su juridicidad y estableciendo sus efectos como de naturaleza fundamentalmente política (aspiraciones o fines). La anterior afirmación deriva principalmente de la teoría que los distingue de los derechos civiles y políticos (Atria, 2002), sustentada históricamente durante gran parte de los siglos XIx y $x x$, situación que se refleja en un sinnúmero de constituciones (Argentina, Colombia, Ecuador, Perú) e instrumentos internacionales de protección de derechos humanos.

El proceso histórico de resistencia a los modelos económicos y sociales de corte liberal permitió la implementación del Estado social de derecho y con ello la valoración y protección de las necesidades básicas, así como la constitucionalización de los derechos y, en especial, la consagración esencialmente importante de un listado de derechos sociales que garantizaban una existencia acorde con los planes de vida de cada sujeto.

Para acercarnos a una definición omnicomprensiva de los DESc, puede indicarse que estos aluden a derechos de previsión, educación y seguridad social frente a la comunidad y el Estado, que se refieren a beneficios sociales, económicos y culturales que pretenden la reivindicación de una distribución adecuada de los bienes indispensables para la vida y el ejercicio de las libertades civiles y políticas (De Sousa Santos et al., 2001, pág. 15), e indispensables para la existencia digna y el autorrespeto (Arango, 2002, pág. 105).

LOS DESC son derechos con contenido prestacional y limitativo o restrictivo para el Estado, con el fin de atender de forma prioritaria necesidades que permiten ejercer de forma igualitaria las libertades esenciales y desarrollar un plan autónomo de vida que integre de forma coherente la dignidad a la esfera individual y social de las personas. Dichas garantías están dirigidas a grupos históricamente marginados o discriminados, y están contenidas en instrumentos tanto internos (constitucionales) como internacionales.

Se resalta de esta propuesta que la libertad, autonomía e igualdad son una condición triádica esencial para la juridicidad, que integra los elementos sociológicos, políticos y axiológicos presentes en un ordenamiento jurídico, toda vez que reconoce una esfera individual, social y valorativa del individuo para traslaparla con un contenido garantístico desde el derecho.

Por otro lado, implícita en la explicación de los derechos sociales se encuentra la dignidad humana como valor fundamental de los Estados sociales y constitucionales que pregonan una democracia humanista, considerando al individuo aislado y soberano propio del Estado liberal como un ser socialmente solidario, que se debate en la incertidumbre del mercado capitalista y que necesita de la sociedad y el Estado para sortear estas inseguridades. De acuerdo con Baldassarre et al., (2001, pág. 30), 
la libertad negativa ya no es un bien en sí sino que lo es en cuanto parte o aspecto del concepto más comprensivo de libertad positiva, puesto que sin este nexo también la libertad negativa, no menos de los derechos sociales, puede muy bien ser compatible con un régimen totalitario, la igualdad no puede definirse solo en una perspectiva de garantía o de salvaguarda (si no de conservación) de la distribución natural de los recursos (igualdad formal) ni por el contrario, como concepto que borra del todo el valor de la libertad es decir como distribución de beneficios sociales según las necesidades de cada quien (igualitarismo) sino que el tenerse que conjugar con la libertad positiva y por tanto con la autorrealización personal debe determinarse en principio como igualdad de las condiciones de partida o más exactamente de las oportunidades (es decir como igualdad sustancial).

Por consiguiente, los DESC y la dignidad constituyen un principio constitucional que irradia y condiciona la validez de todo el ordenamiento jurídico, de modo que permite el posicionamiento superior de la persona sobre cualquier otro elemento, y estructura alrededor de esta supremacía los derechos fundamentales, dentro de Ios cuales encuentran Ios DESc su justiciabilidad directa, bajo una conjugación de instrumentos constitucionales e instrumentos internacionales de protección de los derechos humanos de forma interdependiente (Herreño, 2008, pág. 25).

Indica lo anterior que debe existir un grado mínimo de justiciabilidad de los DESC, toda vez que esto cualifica la democracia constitucional y asegura la procura existencial mínima de las personas garantizada constitucionalmente, es decir, todo derecho necesita de la existencia de garantías institucionales que permitan la exigibilidad de su protección o violación, por lo tanto es necesario asegurar la libertad bajo medios jurisdiccionales o de tipo administrativo que permitan a los afectados reclamar (Ruiz y Plazas, 2011).

LOS DESC se consideran entonces derechos para el ejercicio de libertades igualitarias bajo la protección del plan de vida individual o grupal de cada miembro de la sociedad, fortalecidos por las normas constitucionales que señalan a grupos especiales o marginados prioridad en la asignación de bienes básicos que les aseguran una existencia digna, acompañadas de normas de procedimiento de ejercicio y actuación. Se deriva de los anteriores apuntes que la individualización normativa y procedimental de los derechos constituye un elemento central de la protección y exigibilidad.

El actual sistema constitucional y la posición fuerte de la norma suprema como pauta jurídico-axiológica suponen un giro metodológico (Chinchilla, 2009) de estudio de los derechos, importante para la comprensión de su protección, al considerar que los derechos fundamentales son derechos en la medida que: 1) salvaguardan situaciones valiosas para las personas $y$, por ende, reciben el manto de protección del ordenamiento jurídico, y 2) suponen un contenido axiológico y valorativo relativamente alto, que según Chinchilla (2009) supera la estructura lógica de la regla Kelseniana para quien toda norma que acarrea sanción o consecuencia jurídica, indicada semántica y enunciativamente, 
es norma jurídica completa. Sin embargo hoy, bajo este nuevo panorama, todo juez u operador jurídico que encuentre una norma con un enunciado que garantice o señale la existencia de un derecho, es una norma jurídica plenamente aplicable y por lo tanto destinataria de acción judicial de reclamación en caso de denegación o violación.

\section{EL CONTROL SOCIAL, LA DEMOCRACIA Y LOS DERECHOS ECONÓMICOS, SOCIALES Y CULTURALES}

El reconocimiento de las libertades esenciales (en sentido positivo), especialmente de los DESC, favorece la comprensión de unos derechos humanos reforzados a través de la norma constitucional, que a su vez se configuran en límites para las acciones estatales y posibilitan ejercer el control democrático necesario para la eficacia real de protección de la dignidad humana, las libertades esenciales y la posibilidad de ejecutar un plan de vida acorde con las capacidades de cada sujeto o grupo de individuos.

La asignación de juridicidad y posibilidad de reclamación jurisdiccional de los derechos sociales encuentran en el Estado social, democrático y constitucional de derecho su ámbito de aplicación y protección más adecuado; dicho escenario, además de propiciar el ejercicio de los mecanismos de reclamación por omisión de amparo, protección defectuosa o acciones violatorias de los derechos sociales, abre la puerta a la participación ciudadana a través del acceso a la información, la estructuración de políticas públicas y su evaluación, el ejercicio de control social sobre las acciones estatales dirigidas a la satisfacción de intereses generales o acciones de atención social a población vulnerable, así como sobre el desempeño de sus gobernantes sobre la lectura de lo que acontece en la sociedad y las necesidades insatisfechas de los gobernados.

Por lo tanto, como resultado del ejercicio democrático enfocado en la exigibilidad de los DESC, es posible hallar un mecanismo de control que refuerce la participación social (veedurías ciudadanas, cabildos abiertos, participación en órganos corporados de dirección en entidades prestadoras de servicios públicos domiciliarios) y a su vez genere espacios de intervención y reducción de la corrupción por parte de los agentes del Estado. El control sobre el gasto y los dineros públicos, como ejercicio de participación social democrática para la satisfacción de los DESC, permitirá la eliminación efectiva de este fenómeno indeseable que, coincidencialmente, es la excusa para la regresividad y poco avance hacia la protección eficiente de los mencionados derechos.

La exigibilidad de los DESc necesariamente supone una intervención de impacto judicial y, consecuencialmente, un impacto social que a su vez tiene injerencia en la arena política, generando instrumentos de monitoreo y control de políticas públicas de tipo socioeconómico sobre las administraciones y el ejercicio del Estado. Tales herramientas, por su parte, serán producto de la negociación política y la opinión pública, con 
lo cual la protección de los DESC concluye en un ejercicio de fortalecimiento de la democracia (Cunill, 2009), toda vez que dichos espacios de protección pueden tener un origen jurisdiccional, pero también de activismo político-institucional por parte de grupos sociales.

Este ejercicio de derechos sociales y de construcción del control social generador de espacios democráticos de diseño de políticas públicas se asume a través de la contraloría social, entendida como sistema de estrategias y acciones que fiscalizan y regulan la satisfacción de necesidades sociales por parte del Estado (Cunill, 2009) en una participación social autónoma pero mancomunada con este, con el fin de que tales políticas reflejen los intereses de la comunidad en general y contribuyan a la construcción de una ciudadanía independiente y fortalecida.

El control social a través de la participación y exigibilidad de los DESC se puede identificar con los momentos ex ante y ex post del ejercicio de las acciones y el poder estatal en la configuración de las políticas públicas. Ex ante a la ejecución de los programas el control y fiscalización se dirige precisamente a evitar y prevenir que las políticas sociales desconozcan o no respondan a los intereses y necesidades de las poblaciones beneficiarias, y a prohibir la ausencia o la precaria concertación con las comunidades en el diseño de estas, para prever estrategias parciales o que no generen impacto positivo en los sujetos objetivo (Cunill, 2009). Los controles de fiscalización ex post van dirigidos a determinar la eficacia y el impacto real que generó la implementación de las políticas sociales, mediante in- dicadores o mediciones técnicas de conversión de las políticas en satisfacción de necesidades, parametrización de las posibilidades reales de acceso a bienes básicos, progresividad en la protección de los DESC y en general acciones que conjugan estrategias políticas y estudios técnicos que son una herramienta de la participación social. Los dos momentos de control tienen la virtud de congregar a la comunidad en torno a la idea humanista de justicia social con la cual evaluarán la satisfacción de los DESc, aportar a la educación cívico-política y generar espacios de proposición (límite a su vez) frente a futuras acciones del Estado, vía una mayor concertación y, como consecuencia, mayor eficacia de las políticas diseñadas.

Estos controles anteriores y posteriores a la implementación de acciones sociales permiten diseñar y ejecutar las políticas públicas con enfoque de derechos humanos, y una visión integral del individuo como sujeto de derechos, con autonomía en la decisión y ejecución de su plan de vida, propósito en el que la satisfacción de las necesidades y el acceso a bienes básicos (DESC) son un elemento trascendental, así como en la protección de todas sus libertades y su dignidad (Abramovich, 2006, pág. 36).

Sin duda estas experiencias, aunque carentes de perfección, han garantizado en un nivel deseable la participación de la comunidad objeto de la medida en alguna de las etapas y han aportado a la consolidación del individuo como un ser autónomo, educado políticamente, sujeto de derechos y eje central del moderno Estado de derecho. 
Esto garantiza que bajo una fórmula que respete la dimensión de derechos de las necesidades y entienda que la integralidad de la pobreza, la discriminación social y la ausencia de libertades en el plan de vida de los sujetos se zanja definitivamente a través de la protección de los DESC, indefectiblemente abogará por asegurar la exigibilidad jurisdiccional de estos (Cunill, 2009).

Si bien este control social es una iniciativa esencialmente comunitaria, es necesario comprender que su ausencia, poco fortalecimiento y falta de ejecución, por lo menos en Colombia, se enmarcan en un contexto de vulnerabilidad de las comunidades, por cuanto los esfuerzos de estas se dirigen principalmente al sostenimiento y satisfacción parcial de necesidades básicas al margen de las acciones del Estado y, por lo tanto, no han tenido repercusión en las políticas públicas formuladas, a pesar de que entienden que en la espera de aquellas pueden poner en riesgo su vida y la de sus parientes cercanos.

A esta situación se suman la escasa educación cívico-política y la falta de interés del Estado en brindar un nivel adecuado de educación que garantice la participación política de la ciudadanía. En concepto del Programa de las Naciones Unidas para el Desarrollo (PNUD), citado por CuniII (2009. pág. 21), “Uno de los grandes obstáculos para lograr la participación social en el monitoreo es la percepción por parte de la sociedad de que hay poca capacidad de sanción en la administración pública”. Por eso, no solo cabe abogar por instituciones judiciales y de control, fuertes e independientes, sino por una cultura de contraloría social de poderes directos, que como tal no están mediados por la institucionalidad contralora o judicial para su activación sino por el número. De hecho, las movilizaciones y protestas remiten a las formas más tradicionales de sanciones directas a que puede apelar el control social para generar consecuencias sobre los poderes públicos. Pero las sanciones que se aplican a través del ejercicio de este tipo de poder suelen ser simbólicas y, por lo tanto, sin efectos mandantes. Solo la resonancia y la persistencia del poder del número pueden generar consecuencias, tal como lo muestran, por ejemplo, los casos de más de una docena de presidentes que entre 1978 y 2005 han debido dejar sus cargos antes del término de su mandato constitucional (Cunill, 2009, pág. 9).

Un avance importante para la consolidación del control social a través de la exigibilidad de protección de los DESC ha sido la supervisión que los jueces y los tribunales constitucionales han implementado sobre el cumplimiento de los fallos de tutela o de mecanismos de amparo, toda vez que impactan de forma directa o mediata. Para citar un ejemplo, está la sentencia T-411 de 2009 de la Corte Constitucional atinente al derecho a la igualdad de grupos sujetos de especial de protección (recuperadores ambientales de Cali) a causa de su discriminación y marginación social, violentados en la protección de los DESC, y a quienes además les ha sido negada su participación en la construcción de la democracia. Estos incidentes propuestos por las cortes no pretenden dirigir el gasto público, sino combinar estrategias de participación de la población beneficiaria de la medida en la elaboración de las políticas o acciones afirmativas ne- 
cesarias para la protección y el restablecimiento de sus derechos humanos. Otro ejemplo es la sentencia T-025 de 2004 de la Corte Constitucional, que declaró el estado de cosas inconstitucionales en la atención integral y protección de derechos humanos y condiciones socioeconómicas dignas de la población desplazada, obligando al Estado a implementar un sinnúmero de políticas y acciones para superarlas, como son la adopción del Plan Nacional de Atención Integral a la Población Desplazada por la Violencia y varios programas nacionales, regionales y municipales en favor de los grupos vulnerados. Sin embargo, la sentencia en el caso de los desplazados tiene un efecto instrumental y un componente simbólico. Su situación sigue siendo grave y el gobierno no ha logrado unificar los sistemas de información entre sí mismo y las demás instituciones. En cuanto a los DESc, hay una variación mínima en su mejoramiento pero no tan significativa como se quisiera (Arcidiácono, Espejo, Yaksic y Rodríguez, 2010), explicable en razón de que exige un cambio de paradigma en la inversión social y en la fundamentación de la educación como componente esencial del desarrollo humano, y con ello del fortalecimiento del control social como herramienta liberadora y emancipadora de estigmas como la situación de pobreza y la marginación socio-cultural.

La participación democrática y el ejercicio de controles sociales tienen una relación directa con la exigibilidad jurisdiccional, y la posibilidad de reclamar en instancias judiciales la satisfacción de derechos sociales como alternativa a su control social, permitiendo incorporar dentro de los asuntos y temas ventilados ante los jueces los DESC y la protección de la participación social en el diseño de políticas públicas que protegen los derechos sociales (Abramovich, 2007, pág. 11).

El medio judicial es una alternativa de organización del control social y del ejercicio de la autonomía política, que va generando la movilización y la cohesión de las comunidades en torno a sus intereses y reclamos, a través de la impugnación de decisiones estatales, de deslegitimación de medidas regresivas o poco progresivas, de ventilación de la corrupción estatal y, en definitiva, de control de la administración de los recursos públicos.

No cabe duda de que la implementación de derechos a través de políticas públicas depende de actividades de planificación, previsión presupuestaria e implementación que por naturaleza corresponden a los poderes políticos, siendo limitados los casos en los que el poder judicial puede llevar a cabo la tarea de suplir la inactividad de aquellos. Sin embargo, aun en estos casos los márgenes de actuación de la magistratura son variados y los tribunales han encontrado la manera de garantizar la vigencia de los derechos afectados (Abramovich, 2007, pág. 14).

\section{LAS POLÍTICAS PÚBLICAS Y LOS DESC}

Con la entrada del neoliberalismo se produjeron impactos sociales, económicos y políticos trascendentales. Uno de ellos fue la combinación de estrategias políticas con tinte social de legi- 
timación de recortes económicos asistenciales impregnando toda la sociedad de una dinámica economicista de precaria satisfacción de necesidades, y la revitalización de la no intervención bajo la premisa de la salvación y el aseguramiento de niveles de vida adecuados dentro de los espacios del mercado.

En Latinoamérica se produjo un choque con los modelos asistencialistas y socialistas del intervencionismo en el mercado con el fin de implementar una igualdad social absoluta. Esto degeneró en ausencia de políticas sociales que sortearan los riesgos de la vida en sociedad de las personas y la insatisfacción de necesidades que no podían buscarse en igualdad de condiciones en el mercado, así como en insuficiencia para lograr la justicia social que el neoliberalismo pretendía.

Esto fue reforzado por líderes populistas que en todo el sur del continente americano tomaron el poder de forma seudodemocrática, queriendo legitimar la prevalencia de intereses que no incluían la participación social y popular amplia, y que a través de propuestas de desarrollo impregnaron valores de insolidaridad y división de la cohesión social, minando la dimensión humanista de los derechos y los sujetos sociales, así como de sus necesidades.

La gobernabilidad pasa de ser entonces legitimidad y coherencia de las acciones estatales con las necesidades sociales a un eficientismo parametrizado de participación parcial o mentirosa de la población en medidas que se pretenden presentar como logros sociales, encubriendo in- tereses financieros muchas veces antidemocráticos (Fleury, 2004, pág. 67).

Como consecuencia este sistema de política económica que desplazó al escenario de política democrática de participación social, no generó sostenibilidad y gobernanza en torno a la satisfacción de ideales comunes, sino que construyó mayor exclusión y situación de pobreza; los mercados son incompetentes para construir ciudadanía y protección de los derechos humanos y con ello de los DESC.

Esta situación creó unas paradojas negativas de la democracia, tales como: la democracia sin política, bajo modelos economicistas a gran escala que suplantaron el poder de decisión política por el imperativo financiero; una democracia sin inclusión, es decir, con ausencia de distribución de las fuentes de riqueza y marginamiento de grupos poblacionales vulnerables; y una democracia sin poder legitimado por vías políticas, sino económicas (Fleury, 2004, pág. 69).

El desarrollo ha estado al margen de las poblaciones destinatarias de los derechos humanos y ha sido fragmentado por el comodín del interés general y la supuesta justicia social, antes que responder a la inclusión o ser favorable a las capacidades sociales e individuales de los sujetos y la sociedad. Ha sido un desarrollo monótono entre grupos económicos, orientado al saneamiento del componente financiero de los Estados, permeando de forma, inclusive ilegítima, todas las actuaciones estatales. 
La constitucionalización de los derechos humanos, entendidos de forma interdependiente, entre ellos los DESc, establece un margen de acción amplísimo y favorable para las acciones de desarrollo en materia de asistencia social por parte del Estado. Tal incorporación le impone, por un lado, obligaciones mínimas negativas que debe satisfacer mediante sus políticas públicas, tales como la prohibición de discriminación, de prestación deficiente en casos de perjuicio irremediable, de regresividad o implementación irrazonable; y, por otro lado, acciones positivas, "por ejemplo, brindar ciertas prestaciones o servicios a grupos especiales en situaciones de desigualdad estructural, organizar prestaciones básicas para cubrir necesidades de subsistencia, servicios de educación, salud o de acceso a una vivienda" (Pautassi y Abramovich, 2009, pág. 1), de lo que se infiere que el margen de discrecionalidad es restringido en favor de la aplicación y cumplimiento efectivo de las obligaciones constitucionales e internacionales.

De esa forma, la inclusión y reconocimiento constitucional de los derechos sociales determina un campo de acción fundamentado en los derechos humanos, para la estructuración, acceso, ejecución e implementación eficiente de las políticas públicas para población vulnerable y discriminada históricamente,

en la medida en que pueden determinar el acceso a prestaciones relacionadas con derechos fundamentales, deben cumplir también con ciertos requisitos mínimos de debido proceso que funcionan en definitiva como garantías del acceso a derechos... plazos razonables, es- pacios de participación, criterios objetivos de adjudicación, rechazo de arbitrariedad, posibilidad de quejas y notificación debida (Abramovich y Pautassi, 2009, pág. 2).

El acceso a la efectiva realización de los DESc por medio de políticas públicas cualifica la relación del Estado con los ciudadanos, dotando de legitimidad sus acciones y procedimientos, asegurando la compatibilidad y cumplimiento de sus programas sociales con los parámetros constitucionales y los instrumentos internacionales. Un Estado que actúa a través de políticas públicas con enfoque de derechos humanos asegura que la distribución de la riqueza y los bienes escasos sea equitativa; es una democracia en vías de consolidación con amplios márgenes de legitimidad política, que permite unos mínimos de autonomía personal y política de sus asociados, toda vez que su plan de vida será un proyecto real.

Sin embargo, la construcción de la sociedad y su relación con el Estado a través de las políticas públicas está despertando de la ausencia en la que estuvo durante el tiempo de visión eficientista y gerencial (Canto, 2008); la satisfacción de necesidades sociales a través de acciones estatales se está condicionando cada vez más a una participación activa y a una visión integral del ser humano, desburocratizando los programas sociales estatales que se encontraban en una especie de privatización y parametrización de los resultados con base en la legitimidad del Estado y no en la real protección de los DESc y las libertades. 
Los jueces proveen entonces justicia constitucional transformadora del entorno social, que permite indudablemente la consolidación del Estado social de derecho y, por ende, fortalecer la participación democrática en tanto permite a todos los actores sociales vigilar y fiscalizar la ejecución eficiente de las políticas públicas que implementa el Estado,

la evaluación de los efectos posibles de un proceso de judicialización de las políticas dependerá de la ponderación de numerosos factores: el alcance del reconocimiento de estos derechos en la constitución y en las leyes; la interpretación constitucional de las obligaciones que originan; la capacidad de actores sociales relevantes para actuar en representación de los intereses de grupos discriminados o excluidos; el grado de organización y fortaleza de la sociedad civil y su experiencia y capacidad técnica para hacer uso de las herramientas legales; la mayor predisposición de los tribunales a enfrentar este tipo de cuestiones; los sistemas de procedimientos más abiertos o cerrados, y el tipo de remedios $u$ órdenes que los jueces están habilitados para disponer; los mecanismos de selección de los jueces y la independencia (Pautassi y Abramovich, 2009, pág. 42).

La ausencia de acciones efectivas es igualmente un campo de acción para la justiciabilidad de las políticas públicas, toda vez que los órganos estatales en estos casos de omisión incumplen obligaciones de protección normativa tanto a nivel constitucional como internacional, y los tribunales constitucionales, como la Corte Constitucional de Colombia, por ejemplo, declaran un estado de cosas inconstitucional que determina un margen de acción positiva para superar la violación que genera la omisión de protección. Es importante entender aquí que las sentencias que ordenan protección son instrucciones generales para los órganos ejecutores, toda vez que los jueces tienen una imposibilidad técnica y democrática para determinar con precisión el gasto público y específicamente formas de maniobra y destinación de la asistencia social y, de esta forma, asegurar tanto la participación democrática de toda la sociedad como permitir al Estado-Administración corregir su rumbo y concebir en adelante las políticas públicas con un enfoque más integral en términos de derechos humanos.

Es válido anotar también que la exigibilidad fundamental de IOS DESc ha sido aplazada paradójicamente por razones "democráticas" en nuestro contexto colombiano, por cuanto son derechos de protección progresiva y garantía limitada, lo que de conformidad con todo lo mencionado hasta ahora debe ser matizado y sometido al filtro del Estado social de derecho (CConst., T-406 de 1992), por cuanto democráticamente las necesidades, bienes básicos y exigencias de distribución de la riqueza garantizan todas las libertades humanas y fortalecen la democracia participativa; es decir, histórica y constitucionalmente la ciudadanía y la democracia no garantizan su éxito solo protegiendo los derechos civiles y políticos de forma prioritaria, y después los derechos sociales, la democracia se garantiza a partir de solventar las necesidades e intereses humanos mediante la concertación o favorecimiento de la participación social (Gargarella, 2006, pág. 10). 
Por lo tanto es necesario superar la visión empobrecida del ser humano y caritativa del Estado, para construir un sujeto que se vaya educando políticamente de acuerdo con sus contextos, sensible a sus entornos, que genere espacios de discusión locales a través de sistemas complejos de necesidades vitales concentrados en sus vecinos, que motive una participación social organizada que movilice cada vez más los sujetos y los encuentre con el Estado. Lo anterior con el fin de entender y mejorar la consolidación de una participación que permita la construcción de mecanismos que arropen a los afectados por la ausencia de protección de los DESc.

La participación política supera la visión simplista del sufragio como máxima expresión de la democracia participativa, toda vez que la representación ha caído en deslegitimación y ausencia de responsabilidad social y política, lo que genera espacios de participación directa y más eficientes, condicionando la representatividad a la coherencia del ejercicio político de los elegidos con la satisfacción y protección de derechos, especialmente de loS DESC. La participación política se amplía a formas y mecanismos innominados, pero constitucionalmente relevantes para la construcción de ciudadanía y del desarrollo basado en derechos que servirán de sustrato a la formulación de políticas públicas.

\section{CONCLUSIONES}

1. El reconocimiento de los DESc es un paso fundamental para la consolidación del Estado social, democrático y constitucional de derecho, por cuanto su contenido dignificante y liberador exige una mayor protección y progresividad en la garantía de tales derechos.

2. La prevalencia e importancia de los DESC se debe principalmente al surgimiento del Estado social de derecho junto con una norma constitucional fuerte. Se trata de una simbiosis necesaria y consolidadora de la dignidad humana y del ejercicio de libertades bajo una comprensión plena del ser humano y su proyecto de vida autónomo.

3. LOS DESC se convierten en un filtro de construcción de ciudadanía y democracia a través de la participación propiciada por la exigibilidad judicial, política y social del cumplimiento de las obligaciones que de ellos se derivan.

4. La educación cívico-política es un elemento trascendental en la conformación de los grupos sociales que exigen la protección de los DESc, y por lo tanto un componente esencial en el ejercicio del control social derivado de la práctica de los derechos sociales.

5. Las instancias judiciales de exigibilidad de los DESC se compaginan y abren espacios cada vez más influyentes, reales y autónomos de participación ciudadana en la estructuración de políticas públicas para población vulnerable.

6. La participación social y democrática no se agota en el ejercicio del sufragio, que cada vez más requiere de otras alternativas para resignificar la democracia, tales como la contraloría social antes y después de implementadas las 
políticas públicas por parte del Estado, con un resultado de legitimidad e independencia que consolida la ciudadanía en posiciones y valores compartidos en torno a la satisfacción de necesidades apremiantes y dignificantes.

7. Existe entonces una relación directa y necesaria entre la esencia iusfundamental de IOS DESC y la contraloría social, que permite el ejercicio de exigibilidad de los derechos sociales y la consolidación y cohesión social democratizadora de la participación en torno a la construcción de acciones de asistencia social para población vulnerable, bajo el círculo virtuoso del enfoque de derechos humanos en las políticas públicas.

8. Los controles garantizan el cumplimiento de IOS DESC, a través de la participación social que genera una ciudadanía mucho más educada y preparada para situaciones y contextos que la convierten en población altamente vulnerable, evitando la ocurrencia de tales condiciones de existencia.

\section{Referencias}

Abramovich, V. (2006). Una aproximación al enfoque de derechos en las estrategias y políticas de desarrollo. Revista de la CEPAL, (88), 35-50.

Abramovich, V. (2007). Acceso a la justicia y nuevas formas de participación en la esfera política. Estudios Socio Jurídicos, (9), 9-33.

Arango, R. (2002). Promoción de los derechos sociales constitucionales por vía de protec- ción judicial. Revista el Otro Derecho, (28), 103-122.

Arcidiácono, P., Espejo, N., Yaksic, C. y Rodríguez, C. (2010). Derechos sociales: justicia, política y economía en América Latina. Bogotá: Siglo del Hombre Editores, Universidad de los Andes.

Atria, F. (2002). ¿Existen derechos sociales? Trabajo preparado para su presentación en las XVI Jornadas Argentinas de Filosofía Jurídica y Social, realizadas los días 24, 25 y 26 de octubre de 2002 en Buenos Aires.

Baldassarre, A., Villar Borda, L. y Perea, S. (2001). Los derechos sociales. Bogotá: Universidad Externado de Colombia.

Canto Chac, M. (2008). Gobernanza y participación ciudadana en las políticas públicas frente al reto del desarrollo. Política y Cultura, (30), 9-37.

Chinchilla, T. E. (2009). ¿Qué son y cuáles son los derechos fundamentales? Bogotá: Temis.

Corte Constitucional Colombia. Sentencia T-406 de 1992. (M. P.: Ciro Angarita Barón: junio 5 de 1992).

Corte Constitucional de Colombia. Sentencia T-025 de 2004. (M. P.: Manuel José Cepeda Espinosa: enero 22 de 2004).

Corte Constitucional de Colombia. Sentencia T-411 de 2009. (M. P.: María Victoria Calle Correa: junio 23 de 2009). 
Cunill Grau, N. (2009). Contraloría social y derechos sociales. El desafío de la integralidad. Gestión y Política Pública, XVIII(1), 3-37.

De Soussa Santos, B., Van Parijs, P., Gosepath, S., Cortés, F., Giraldo, J., López, L. y Arango, R. (2001). Ciudadanía y derechos humanos sociales. Medellín, Colombia: Ediciones Escuela Nacional Sindical.

Fleury, S. (2004). Ciudadanías, exclusión y democracia. Nueva Sociedad, (193), 62-75.

Garagarella, R. (2006). ¿Democracia deliberativa y justiciabilidad de los derechos sociales? Perfiles Latinoamericanos, (28), 9-32.

Gutiérrez Beltrán, A. M. (2010). Tendencia actual de amparo en materia de derechos económicos, sociales y culturales en la jurisprudencia de la Corte Constitucional. Revista Derecho del Estado, (24), 13-30.

Herreño Hernández, Á. L. (2008). ¿Todo o nada? principio de integralidad y derechos sociales. Bogotá: Instituto Latinoamericano de Servicios Legales Alternativos (ILSA).

Putassi, L. y Abramovich, V. (2009). La revisión judicial de las políticas públicas. Buenos Aires: Editores del Puerto.

Ruiz, R. y Plazas C. (2011). La exigibilidad de los derechos sociales. El caso de Colombia. Universitas, Revista de Filosofía, Derecho y Política, (14), 3-20. 